\title{
Development of a Virtual Training Program to Reduce Gun Violence Amidst the Covid-19 Era
}

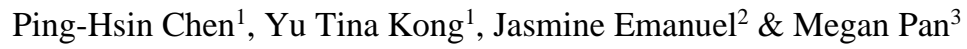 \\ ${ }^{1}$ Department of Family Medicine, Rutgers New Jersey Medical School, Newark, NJ, USA \\ ${ }^{2}$ Rutgers University, New Brunswick, NJ, USA \\ ${ }^{3}$ J. P. Stevens High School, Edison, NJ, USA \\ Correspondence: Ping-Hsin Chen, Rutgers New Jersey Medical School, Newark, NJ 07103, USA.
}

Received: January 5, 2021

Accepted: February 6, 2021

Online Published: February 7, 2021

doi:10.11114/jets.v9i2.5121

URL: https://doi.org/10.11114/jets.v9i2.5121

\begin{abstract}
Firearm deaths and related health issues have increased and disproportionately affected minorities in the COVID-19 era. We developed an accessible virtual training program, including topics on gun violence epidemiology, depression, substance use, intimate partner violence (IPV), intervention resources, safety planning, and COVID-19-related issues. The training program was distributed to participants from the Northeast region, particularly New Jersey, through text, email, and social media. Among the 202 survey responses from the participants, the mean age was $22.6,50 \%$ were male, and $84.4 \%$ were minorities. Only $49.5 \%$ of participants were familiar with the related topics before the program, with participants having the least knowledge in gun violence epidemiology (9.5\%). The mean test score for knowledge on all related topics after the training was 98.0 out of 100. Most participants were satisfied with the training program (92.1\%), felt comfortable seeking help (86.1\%), and would promote the program (83.7\%). The participants were least comfortable seeking help for depression, particularly among non-African and non-Hispanic minority groups. We concluded that brief online interventions can improve community health outreach, knowledge, awareness, and likelihood of help-seeking and treatment. Tailored training programs are needed to target various populations for prevention and intervention.
\end{abstract}

Keywords: gun violence, prevention, training program, virtual, minority, young adults

\section{Introduction}

\subsection{Prevalence and Consequences of Gun Violence}

Gun violence is a major public health concern in the U.S. Nationally, over 620,000 individuals died from firearm violence from 2000-2018, with nearly 40,000 deaths associated with gun violence in 2017 alone (CDC, 2020). Among the fatal injuries, $60 \%$ were suicide and $36.6 \%$ were homicide (Kochanek et al., 2019). Guns are the leading method of suicide and homicide in the U.S., accounting for over $50 \%$ of all suicide deaths and $75 \%$ of all homicide deaths (CDC, 2020; Brady Center to Prevent Gun Violence, 2016). Nonfatal gun injuries have also increased significantly, rising from 63,000 in 2001 to 85,000 in 2015 (CDC, 2020). For every victim of fatal gun violence, two more victims sustain nonfatal gun injuries (Everytown for Gun Safety Support Fund, 2019).

\subsection{Risk Factors of Gun Violence}

Previous studies of firearm injuries have examined selected demographic, clinical, and circumstantial factors. The death rate for firearm injuries for males was 6.1 times the rate for females (Kochanek et al., 2019). Among victims of violent crimes, African Americans, Hispanics, and Asians were more likely than Caucasians to face an offender with a firearm $(14 \%, 10 \%, 14 \%, 7 \%$, respectively) (Harrell, 2009). The firearm death rate for African Americans was the highest among all races (Kochanek et al., 2019). African American and Hispanic communities are disproportionately burdened by gun violence (Chandler, 2018). Firearm homicide is the second leading cause of death among youth, often in the context of crime and violence (CDC, 2020; Fowler et al., 2017). One in six firearm injuries affects a child or teenager, after which the injury rate peaks at young adults aged 20 to 24 years before decreasing (Everytown for Gun Safety Support Fund, 2019).

Mental illness and general medical disorders are strong factors in suicide, which accounts for the majority of firearm 
deaths (Boggs et al, 2018; Li et al., 2011; Swanson et al, 2016). Minority patients' emotional or behavioral problems are often misdiagnosed or underdiagnosed (Liang et al., 2016; Woodward et al., 2013). Minority patients are less likely to receive treatment for their mental health. In 2015 , for adults with mental health issues, $48 \%$ of Caucasians received mental health services, while only $31 \%$ of African Americans and Hispanics, and $22 \%$ of Asians received treatment (American Psychiatric Association, 2019).

Alcohol and substance use were significantly associated with suicide and intimate partner homicide by firearms (Branas et al., 2016; Roberts, 2009; Chen \& Wu, 2016; McGinty \& Webster, 2017; McGinty et al., 2016). While minorities have similar rates of substance use disorders compared to Caucasians, they are less likely to use specialty treatment services or complete treatment for substance abuse (Perron et al., 2009; Saloner \& Cook, 2013).

In 2013, more than half (53\%) of the intimate partner homicides, which often involved children as well, in the U.S., were committed with firearms (Fowler et al., 2016; Federal Bureau of Investigation, 2015). Minority couples are two to three times more likely to report intimate partner violence (IPV) than Caucasian couples (Caetano et al., 2005). However, minority women are less likely than Caucasian women to use social services, battered women's programs, or seek help from health care professionals (O'Neal \& Beckman, 2017; National Resource Center on Domestic Violence, 2006).

Situational and relationship problems, including access to firearms and history of abuse, also triggered firearm suicides and homicides (Fowler et al., 2017). Minority adults reported exposure to more adverse childhood experiences than Caucasians (Sheats et al., 2018).

\subsection{Impact of COVID-19 on Gun Violence and Its Risk Factors}

The COVID-19 pandemic has negative effects on public health. Firearms fatalities in the U.S. increased during the pandemic peak in 2020 (March-May) compared to the same period in 2019 (Everytown for Gun Safety Support Fund, 2019). Gun deaths increased by $15 \%$ in April and May 2020 compared to the same months in 2019 (Gun violence archive, 2020). A recent report also showed a higher incidence and severity of physical IPV during the pandemic compared with the past three years (Gosangi et al, 2020; Jetelina et al., 2020). The severity of sexual violence also increased significantly during the pandemic (Gosangi et al, 2020; Jetelina et al., 2020). Reports of IPV dropped by more than half, probably because IPV victims were unable to safely call the hotlines (Fielding, 2020). Such violence has a disproportionate impact on minorities (Fielding, 2020). According to a report published by the Centers for Disease Control and Prevention (CDC) in June 2020, U.S. adults also reported significantly more adverse mental health conditions related to COVID-19 (Czeisler et al., 2020). Compared to other groups, racial/ethnic minorities and young adults reported worse mental health outcomes, more substance use, and increased suicidal ideation (Czeisler et al., 2020).

\subsection{Innovative Virtual Training Program to Reduce Gun Violence during the Pandemic}

Existing gun violence intervention programs identify individuals who are at the highest risk of shooting or being shot to reduce violence through targeted interventions in neighborhood streets, trauma centers, or emergency departments (Affinati et al., 2016; Butts et al., 2015; Dicker, 2016; Marks et al., 2018; Purtle et al., 2015; Shibru et al., 2007; Smith et al., 2013). Primary care has also been identified as an ideal site for gun violence prevention and intervention (Carter et al., 2015; Sexton et al., 2018). The United States Preventive Services Task Force (USPSTF) recommends routine screening for health risk factors for gun violence in primary care settings, including IPV, depression, and substance use (U.S. Preventative Services Task Force, 2019).

During the COVID-19 pandemic, most clinical practices transitioned primarily to telehealth. Studies have shown that telehealth may decrease barriers and increase access to health care (Kruse et al., 2017). This provides opportunities for primary care providers to reach out to underserved members of the community and offer tailored prevention and intervention through new technology. Currently, there is an urgent need due to the pandemic to increase prevention and intervention efforts that address violence-related issues, particularly for minorities and young people (Czeisler et al., 2020).

The objective of the study was to develop an accessible and media-based violence prevention training program that can be easily implemented remotely through a community outreach program. In-person community-based programs have shown very small effect sizes (Doss et al., 2020). Prior research has shown that brief online interventions can overcome the major barriers to attendance and reduce costs of interventions (Williamson et al., 2019). We hypothesize that the training program can improve community health outreach, knowledge, awareness, and likelihood of help-seeking and treatment. 


\section{Methods}

\subsection{Setting and Research Team}

The study was conducted through the Rutgers New Jersey Medical School (NJMS) Summer Student Research Program (SSRP) and Northeast Regional Alliance MedPrep (NERA) Program in 2020. Due to the COVID-19 pandemic, the SSRP and NERA programs were conducted virtually throughout the study period. This study was approved by Rutgers NJMS Institutional Review Board (IRB).

\subsection{Framework}

The research team adapted a framework for community-centered mobile health intervention development (Champoux et al., 2020). The team followed a five-step procedure, one step a day, on a weekly basis. The same five-step procedure was repeated weekly throughout the study period.

Step 1: Literature review and needs assessment. The team reviewed the literature on a selected topic related to gun violence, its risk factors, or intervention strategies.

Step 2: Training session design based on theoretical framework. The team determined the scope and content of the training session on the selected topic based on the literature review.

Step 3: Tailored training content. The team developed draft presentation slides on the selected topic together. Team members then worked individually to develop additional tailored sessions and evaluation surveys on the same topic for various populations.

Step 4: Team review and feedback. Mock presentations on the selected topic were conducted among team members. Each evaluation survey was pilot tested among team members who did not develop the survey. Team members provided feedback on all the presentation sessions. Content validity of the evaluation surveys was reviewed by the research team to ensure that all aspects of the training materials were covered in the questions. Interrater reliability for the research team was assessed for evaluation survey questions. Revisions were made until team members showed agreement on questions and answers. After finalizing the training sessions and evaluation surveys, team members used WebEx recordings, PowerPoint presentations with embedded audio, or YouTube videos to create virtual sessions of the selected topic. Web links of the virtual sessions and evaluation surveys were created for distribution.

Step 5: Implementation. Each team member used various methods to distribute the training program sessions of the selected topic, including emails, social media, text messages, and live virtual presentations.

\subsection{Study Participants and Training Program}

Each training program session was delivered to targeted community networks, such as NJMS affiliated hospitals and clinics, student and faculty groups, local churches, shelters, and other organizations. Participants from these community networks were mainly young adults and minorities from New Jersey and other Northeastern states.

The training program included seven topics for seven weeks, ranging from one to four sessions for each topic. Each session is independent of each other and is approximately 10 minutes long. Table 1 summarized the descriptions of each of the 21 sessions on the seven topics. 
Table 1. Topics and descriptions of the virtual violence prevention training program

\begin{tabular}{l}
\hline Topic and selected content of presentation \\
\hline 1. Gun violence epidemiology: (a) What is gun violence? \\
(b) Suicide. (c) Homicide. (d) Homicide suicide. (e) Other \\
types of gun violence. (f) Gun violence by demographics. \\
(g) Prevalence of gun violence by region.
\end{tabular}

2. Depression: (a) What is depression? (b) Types of depression. (c) Depression in the United States. (d) Depression and gun violence. (e) Coping with stress. (f) Help-seeking and screening. (g) Active coping strategies and resources.

3. Substance use: (a) What is substance use? (b) Common types of drugs. (c) Risk factors of addiction. (d) Physical dangers of substance use. (e) Substance use in the United States. (f) Drug use and gun violence. (g) Help-seeking and treatment.

4. Intimate partner violence (IPV): (a) What is IPV? (b) IPV and gun violence. (c) IPV perpetration risk factors. (d) How to prevent IPV perpetration. (e) IPV victimization. (f) Warning signs for IPV. (g) What victims of IPV can do.

5. Intervention resources: (a) Community based intervention programs. (b) Hospital based intervention programs. (c) Mental consequences of gun violence. (d) Social consequences of gun violence. (e) Physical consequences of gun violence. (f) Treatment, rehabilitation and counseling. (g) Resources for survivors.

6. Safety planning: (a) Gun violence exposure indicators. (b) Gun safety. (c) Gun storage. (d) Gun buyback programs. (e) Crisis assistance. (f) Survival tips. (g) Resources.

7. COVID-19 related issues: (a) What is COVID-19? (b) Incubation period. (c) Symptoms. (d) Emergency warning signs. (e) Resolution. (f) Risk factors. (g) Current updates on COVID-19.
Number of sessions

1

Target population

(1) General population

4

(1) General population

(2) Adolescents

(3) College students

(4) Healthcare providers

4

(1) General population

(2) Adolescents

(3) Children and parents

(4) College students

4

(1) Adult perpetrators

(2) Adult victims

(3) Adolescents

(4) Children and parents

3

(1) General population

(2) High risk

populations

(3) Adolescents

3

(1) General population

(2) High risk

populations

(3) Adolescents

2

(1) General population

(2) Adolescents

2.4 Evaluation Survey

After each session, the participants took a brief anonymous survey, which took less than one minute. Demographics included age, gender, and race/ethnicity. Questions on knowledge change included (1) knowledge prior to the program: degree familiar with the topic; (2) learning experience: how much learned from the session; and (3) knowledge test score after the training: approximately five questions for each training session (total score $=100$ ). Training program evaluation included (1) whether information was presented in a clear manner; (2) satisfaction with the presentation, and (3) likelihood of recommending the program to others. In addition, the likelihood of help-seeking was assessed. A Likert scale ranging from 1 (not at all) to 5 (very much) or true/false questions was developed for questions on knowledge, training program evaluation, satisfaction, and help-seeking. Data were collected using a secure web-based survey and database system.

\subsection{Analysis}

We conducted Chi-square tests to describe participant characteristics by topic. Participant characteristics included age $(<20,20-24,>24)$, gender (male, female, other $(<0.5 \%)$ ), and race/ethnicity (Caucasian, African American, Hispanic, and other). As indicated in Table 1, the seven topics included gun violence epidemiology, depression, substance, IPV, intervention resources, safety planning, and COVID-19 related issues. Chi-square tests were conducted to compare participant knowledge prior to the training and learning experience among topics. We also conduct Chi-square tests to describe participant knowledge prior to the training and learning experience by age, gender, and race/ethnicity. ANOVA 
analyses were conducted to compare the total knowledge test score after the training among topics. The three training program evaluation questions and the likelihood of help-seeking were compared by topic, age, gender, and race/ethnicity using Chi-square tests. All the data were analyzed using IBM-SPSS, Version 26. We set statistical significance at the 0.05 level.

\section{Results}

\subsection{Participant Characteristics}

There were a total of 202 anonymous survey responses from all the sessions. All participants were from the Northeastern region, particularly New Jersey. The mean age was 22.6 and $50 \%$ were male. Most participants were minorities (84.4\%), including African American (7.3\%), Hispanic (8.3\%), and Other (68.8\%). Participants of each session were similar in terms of gender and race/ethnicity $(\mathrm{P}=0.980$ and 0.173$)$. Those who participated in the gun violence epidemiology session were older (mean age $=26.4$ ) than those in other sessions $(\mathrm{P}=0.001)$, and $32.3 \%$ of participants of this session knew someone who has experienced gun violence.

\subsection{Knowledge Change in Topics}

Overall, less than half of the participants $(49.5 \%)$ were familiar with the topics before the virtual sessions. Previous knowledge of topics varied significantly $(\mathrm{P}=0.011)$. Participants had the least knowledge in the gun violence epidemiology (9.5\%), followed by IPV (47.6\%), substance use $(50.0 \%)$, intervention resources $(50.0 \%)$, depression (55.7\%), COVID-19 related issues (61.5\%), and safety planning (64.3\%). Previous knowledge of topics was similar in terms of age, gender, and race/ethnicity ( $\mathrm{P}=0.952,0.198,0.985$, respectively; not shown).

Overall, $87.1 \%$ of the participants stated that they have learned much about the topic. All participants stated that they have learned much on the epidemiology of gun violence, followed by IPV violence $(90.5 \%)$, intervention resources (89.5\%), depression (88.6\%), safety planning (85.7\%), substance use (84.1\%), and COVID-19 (61.5\%) ( $\mathrm{p}=0.074)$. Participants aged 20-24 reported learning more than adolescents and those who were older than $24(91.4 \%, 80.6 \%$, and 73.1\%, respectively; $\mathrm{P}=0.016$; not shown). More Caucasian, African American, and Hispanic participants stated that they have learned much than participants of other race/ethnicity ( $\mathrm{P}=0.017$; not shown). Males and females reported similar levels of information learned ( $\mathrm{P}=0.910$; not shown).

The overall mean test score for knowledge after the training was 98.0 out of 100 . Knowledge after the training was similar in terms of topic, age, gender, and race/ethnicity ( $\mathrm{P}=0.081,0.902,0.947,0.292$, respectively; not shown). Table 2 showed knowledge change by topic.

Table 2. Knowledge change by topic

\begin{tabular}{|c|c|c|c|c|c|c|c|c|c|}
\hline $\begin{array}{l}\text { Knowledge } \\
\text { related } \\
\text { items }\end{array}$ & $\begin{array}{l}\text { Overal } \\
\text { l }\end{array}$ & $\begin{array}{l}\text { Gun } \\
\text { violence }\end{array}$ & Depression & $\begin{array}{l}\text { Substance } \\
\text { use }\end{array}$ & $\begin{array}{l}\text { Intimate } \\
\text { partner } \\
\text { violence } \\
\text { (IPV) }\end{array}$ & Resources & $\begin{array}{l}\text { Safety } \\
\text { planning }\end{array}$ & $\begin{array}{l}\text { COVID } \\
-19 \\
\text { related } \\
\text { issues }\end{array}$ & $\begin{array}{l}P \\
\text { value }\end{array}$ \\
\hline $\begin{array}{l}\text { Knowledge } \\
\text { prior to the } \\
\text { training (\% } \\
\text { familiar } \\
\text { with the } \\
\text { topic) }\end{array}$ & $49.5 \%$ & $9.5 \%$ & $55.7 \%$ & $50.0 \%$ & $47.6 \%$ & $50.0 \%$ & $64.3 \%$ & $61.5 \%$ & 0.011 \\
\hline $\begin{array}{l}\text { Learning } \\
\text { experience } \\
\text { (\% felt } \\
\text { learning } \\
\text { much) }\end{array}$ & $87.1 \%$ & $100.0 \%$ & $88.6 \%$ & $84.1 \%$ & $90.5 \%$ & $89.5 \%$ & $85.7 \%$ & $61.5 \%$ & 0.074 \\
\hline $\begin{array}{l}\text { Knowledge } \\
\text { test score } \\
\text { after the } \\
\text { training } \\
\text { (mean } \\
\text { score, total } \\
\text { score=100) }\end{array}$ & 98.0 & 100.0 & 97.4 & 96.1 & 100.0 & 98.9 & 97.1 & 100.0 & 0.081 \\
\hline
\end{tabular}




\subsection{Training Program Evaluation}

Overall, $99 \%$ of participants felt that the information was presented in a clear manner, regardless of topics, age, gender, and race/ethnicity ( $\mathrm{P}=0.767$ as shown in Table $3 ; 0.843,0.417,0.804$, not shown). Most participants were satisfied with the virtual program $(92.1 \%)$. Satisfaction was similar in terms of topics, age, gender, and race/ethnicity ( $\mathrm{P}=0.724$ as shown in Table 3; 0.836, 0.083, and 0.062, not shown). Most of the participants would recommend it to their family and friends $(83.7 \%)$, regardless of topics, age, and gender ( $\mathrm{P}=0.178$ as shown in Table $3 ; 0.278$, and 0.804 , not shown). Caucasian, African American, and Hispanic participants (100.0\%), compared to participants of other races/ethnicities (76.8\%), were more likely to recommend the virtual programs to family and friends ( $\mathrm{P}=0.001$, not shown).

Most participants (86.1\%) felt comfortable seeking help for themselves or family members, regardless of topics, age, gender, and race/ethnicity $(\mathrm{P}=0.198,0.234,0.925$, and 0.158 , respectively; not shown). Participants appeared to be the least comfortable seeking help for depression (80\%), particularly among non-African and non-Hispanic minority groups (72.5\%) (not shown). Table 3 summarized the training program evaluation by topic.

Table 3. Training program evaluation by topic

\begin{tabular}{|c|c|c|c|c|c|c|c|c|c|}
\hline $\begin{array}{l}\text { Training } \\
\text { program } \\
\text { evaluation } \\
\text { items }\end{array}$ & Overall & $\begin{array}{l}\text { Gun } \\
\text { violence }\end{array}$ & Depression & $\begin{array}{l}\text { Substance } \\
\text { use }\end{array}$ & $\begin{array}{l}\text { Intimate } \\
\text { partner } \\
\text { violence } \\
\text { (IPV) }\end{array}$ & Resources & $\begin{array}{l}\text { Safety } \\
\text { planning }\end{array}$ & $\begin{array}{l}\text { COVID } \\
-19 \\
\text { related } \\
\text { issues }\end{array}$ & $\begin{array}{l}P \\
\text { value }\end{array}$ \\
\hline $\begin{array}{l}\% \text { felt } \\
\text { information } \\
\text { was presented } \\
\text { in a clear } \\
\text { manner }\end{array}$ & $99.0 \%$ & $100.0 \%$ & $100.0 \%$ & $95.8 \%$ & $100.0 \%$ & $100.0 \%$ & $100.0 \%$ & $100.0 \%$ & 0.767 \\
\hline $\begin{array}{l}\text { \% satisfied } \\
\text { with the } \\
\text { virtual } \\
\text { training } \\
\text { program }\end{array}$ & $92.1 \%$ & $100.0 \%$ & $92.9 \%$ & $90.9 \%$ & $90.5 \%$ & $84.2 \%$ & $92.9 \%$ & $92.3 \%$ & 0.724 \\
\hline $\begin{array}{l}\% \text { likely to } \\
\text { promote the } \\
\text { training } \\
\text { program }\end{array}$ & $83.7 \%$ & $100.0 \%$ & $84.3 \%$ & $84.1 \%$ & $66.7 \%$ & $78.9 \%$ & $85.7 \%$ & $84.6 \%$ & 0.178 \\
\hline
\end{tabular}

\section{Discussion}

\subsection{Overall Impact of the Training Program}

To respond to the "pandemic within the pandemic", this project used an innovative virtual approach to improve the delivery of gun violence prevention and intervention programs. Consistent with previous studies on other topics, our project increased the reach for minorities and young people through a virtual training program. In-person community-based programs have shown very small effect sizes (Doss et al., 2020). Minorities and young people are less likely to receive in-person interventions due to scheduling conflicts and transportation issues (Doss et al., 2020; Gaubert et al., 2012). Recent data showed that $96 \%$ of young people ages $18-29$ and more than $80 \%$ of minorities have smartphones (Mobile Fact Sheet. 2020). Brief online interventions can overcome the major barriers to attendance and reduce costs of interventions (Williamson et al., 2019).

\subsection{Urgent Need for Primary Prevention of Gun Violence and Its Risk Factors}

Findings from this study supported the urgent need for translational studies that develop protocols for primary prevention of gun violence and its risk factors. Our study showed that most minorities and young people are not familiar with the epidemiology of gun violence, and the majority are not aware of risk factors and intervention programs. According to a study at a hospital predominantly serving minority patients, of all patients who died due to gun violence, nearly two-fifths (38.5\%) had a history of past outpatient medical visits in their medical records (Chen et al., 2020). Before the pandemic, few patients are asked about the link between health risk factors and firearm exposure and safety in the doctor's office, and the healthcare needs of patients at risk are not being met ((U.S. Preventative Services Task Force, 2019; Roszko et al., 2016). Primary care providers can reach out to the community and offer tailored prevention and intervention through new technology, such as patient portals, telehealth, social media, and text messages. 


\subsection{Tailored Prevention for High-Risk Populations}

Our program showed that the virtual violence training program significantly improves participants' knowledge of gun violence and its related risk factors. Almost all the participants successfully received the take-home message prepared for each topic, regardless of age, gender, and race/ethnicity. The program seems to benefit young adults ages 20-24, Caucasian, African American, and Hispanic groups the most. As these are the groups with the highest risk for gun violence, the training program has addressed specific issues related to homicide and mass shooting, suicide, and IPV for thess populations. Their feedback of learning much from the training program can support the need for tailored prevention to target various groups.

\subsection{Implications}

Most participants felt that the training program was clearly presented, regardless of topic, age, gender, and race/ethnicity. Overall, more than $90 \%$ were satisfied with the training program. However, although all Caucasian, African, and Hispanic participants would recommend the virtual programs to family and friends, only three-fourths of participants of other races/ethnicities would introduce the program to their loved ones. Specifically, they were the least comfortable recommending IPV and gun violence intervention to family and friends. Most participants $(86.1 \%)$ felt comfortable seeking help for themselves or family members, regardless of topic, age, gender, and race/ethnicity. Participants appeared to be the least comfortable seeking help for depression, particularly among non-African and non-Hispanic minority groups. Perhaps, due to cultural barriers, issues with sensitive topics may not be commonly discussed in these minority groups. It is also possible that few research and programs have targeted these populations. Further research is needed to identify barriers of non-African and non-Hispanic minority groups and explore tailored prevention and intervention for these groups.

\subsection{Limitations}

The study has some limitations. The study did not track individuals longitudinally. It is likely that some people participated in multiple sessions. Responses were matched by age, gender, race/ethnicity, topic, and session to identify unique respondents. These results indicated that more than 96 individuals participated in at least one session. Based on a post hoc power analysis, with the estimated sample size of 96 , the study still has more than $80 \%$ of power to detect a small effect size of $5 \%$ on post-intervention knowledge. As the majority stated that they were not familiar with the topics and the posttest knowledge score was 98 out of 100, we believe that the post-intervention knowledge should have been more than 5\%. In addition, the sample may not be representative of general minority populations in the U.S. due to the large number of participants from non-African American and non-Hispanic minority groups. Nonetheless, the study sheds light on the cultural barriers to help-seeking with sensitive topics among these understudied groups.

\subsection{Conclusions}

In conclusion, an online gun violence prevention training program may be effective for community health outreach, particularly during the COVID-19 pandemic era. Minorities and young people may benefit from these programs. Follow-up education sessions should be tailored to target individuals such as non-African American and non-Hispanic minority groups who face barriers to help-seeking. Continuous delivery of the prevention programs through new technology is needed to reduce gun violence and its risk factors.

\section{References}

Affinati, S., Patton, D., Hansen, L., Ranney, M., Christmas, A. B., Violano, P., ... from the Eastern Association for the Surgery of Trauma Injury Control and Violence Prevention Section and Guidelines Section (2016). Hospital-based violence intervention programs targeting adult populations: An Eastern Association for the Surgery of Trauma evidence-based review. Trauma Surgery \& Acute Care Open, 1(1), e000024. https://doi.org/10.1136/tsaco-2016-000024

American Psychiatric Association. (2019). Mental health facts for diverse populations. https://www.psychiatry.org/psychiatrists/cultural-competency/education/mental-health-facts

Boggs, J. M., Beck, A., Hubley, S., Peterson, E. L., Hu, Y., Williams, L. K., ... Ahmedani, B. K. (2018). General Medical, Mental Health, and Demographic Risk Factors Associated With Suicide by Firearm Compared With Other Means. Psychiatric services (Washington, D.C.), 69(6), 677-684. https://doi.org/10.1176/appi.ps.201700237

Brady Center to Prevent Gun Violence. (2016). The truth about suicide \& guns. https://brady-static.s3.amazonaws.com/Report/Brady-Guns-Suicide-Report-2016.pdf

Branas, C. C., Han, S., \& Wiebe, D. J. (2016). Alcohol Use and Firearm Violence. Epidemiologic reviews, 38(1), 32-45. https://doi.org/10.1093/epirev/mxv010

Butts, J. A., Roman, C. G., Bostwick, L., \& Porter, J. R. (2015). Cure violence: a public health model to reduce gun 
violence. Annual review of public health, 36, 39-53. https://doi.org/10.1146/annurev-publhealth-031914-122509

Caetano, R., Field, C. A., Ramisetty-Mikler, S., \& McGrath, C. (2005). The 5-Year Course of Intimate Partner Violence Among White, Black, and Hispanic Couples in the United States. Journal of Interpersonal Violence, 20(9), 1039-1057. https://doi.org/10.1177/0886260505277783

Carter, P. M., Walton, M. A., Roehler, D. R., Goldstick, J., Zimmerman, M. A., Blow, F. C., \& Cunningham, R. M. (2015). Firearm violence among high-risk emergency department youth after an assault injury. Pediatrics, 135(5), 805-815. https://doi.org/10.1542/peds.2014-3572

CDC. (2020). WISQARSTM. Atlanta, GA: CDC National Center for Injury Prevention and Control. Retrieved October 15, 2020 from http://webappa.cdc.gov/sasweb/ncipc/dataRestriction_inj.html.

Champoux, E., Price, R., Cowdery, J. E., Dinh, M., Meurer, W. J., Rehman, N., Schille, C., Oliver, A., Brown, D. L., Killingsworth, J., \& Skolarus, L. E. (2020). Reach Out Emergency Department: Partnering With an Economically Disadvantaged Community in the Development of a Text-Messaging Intervention to Address High Blood Pressure. Health promotion practice, 21(5), 791-801. https://doi.org/10.1177/1524839920913550

Chandler A. (2018) Interventions for reducing violence and its consequences for young black males in America. Cities United. Published 2018. https://bit.ly/2xGoNPG

Chen, D., \& Wu, L. T. (2016). Association Between Substance Use and Gun-Related Behaviors. Epidemiologic reviews, 38(1), 46-61. https://doi.org/10.1093/epirev/mxv013

Chen, P-H., Hohl, B. C., Bonne, S. (2020). Healthcare-seeking behaviors, health risk factors, and forms of firearm death. 48th Annual North American Primary Care Research Group (NAPCRG) Conference.

Czeisler, M. É., Lane, R. I., Petrosky, E., et al. (2020). Mental Health, Substance Use, and Suicidal Ideation During the COVID-19 Pandemic - United States, June 24-30, 2020. Morbidity and Mortality Weekly Report (MMWR), 69, 1049-1057. https://doi.org/10.15585/mmwr.mm6932a1

Dicker, R. A. (2016). Hospital-based violence intervention: an emerging practice based on public health principles. Trauma surgery \& acute care open, 1(1), e000050. https://doi.org/10.1136/tsaco-2016-000050

Doss, B. D., Knopp, K., Roddy, M. K., Rothman, K., Hatch, S. G., \& Rhoades, G. K. (2020). Online programs improve relationship functioning for distressed low-income couples: Results from a nationwide randomized controlled trial. Journal of consulting and clinical psychology, 88(4), 283-294. https://doi.org/10.1037/ccp0000479

Everytown for Gun Safety Support Fund. (2019). A more complete picture: the contours of gun injury in the United States.https://everytownresearch.org/a-more-complete-picture-the-contours-of-gun-injury-in-the-united-states/\#foo t_note_2

Everytown for Gun Safety Support Fund. (2019). Analysis of Gun Violence Archive data. There were 3,259 gun deaths from March 4, 2019, to May 26, 2019, compared with 3,613 gun deaths from March 2, 2020, to May 24, 020.

Federal Bureau of Investigation. (2015). US Department of Justice. Uniform crime reporting program data: Supplementary homicide reports, 2013. https://www.icpsr.umich.edu/icpsrweb/NACJD/studies/36124

Fielding S. (2020). In quarantine with an abuser: surge in domestic violence reports linked to coronavirus. The Guardian. https://www.theguardian.com/us-news/2020/apr/03/coronavirus-quarantine-abuse-domestic-violence

Fowler, K. A., Dahlberg, L. L., Haileyesus, T., Gutierrez, C., \& Bacon, S. (2017). Childhood Firearm Injuries in the United States. Pediatrics, 140(1), e20163486. https://doi.org/10.1542/peds.2016-3486

Gaubert, J. M., Gubits, D., Alderson, D. P., Knox, V. (2012). The supporting healthy marriage evaluation: Final implementation findings (OPRE Report, 20122-12). Washington, DC: Office of Planning, Research and Evaluation, Administration for Children and Families, U.S. Department of Health and Human Services. Retrieved from https://www.mdrc.org/sites/default/files/shm\%20impl\%20full\%20pdf_1.pdf

Gosangi, B., Park, H., Thomas, R., Gujrathi, R., Bay, C. P., Raja, A. S., Seltzer, S. E., Balcom, M. C., McDonald, M. L., Orgill, D. P., Harris, M. B., Boland, G. W., Rexrode, K., \& Khurana, B. (2021). Exacerbation of Physical Intimate Partner Violence during COVID-19 Pandemic. Radiology, 298(1), E38-E45.

https://doi.org/10.1148/radiol.2020202866

Gun violence archive. (2020). https://www.gunviolencearchive.org/

Harrell, E. (2009). Asian, Native Hawaiian, and Pacific Islander Victims of Crime. Bureau of Justice Statistics

Jetelina, K. K., Knell, G., \& Molsberry, R. J. (2020). Changes in intimate partner violence during the early stages of the COVID-19 pandemic in the USA. Injury prevention: journal of the International Society for Child and Adolescent 
Injury Prevention, injuryprev-2020-043831. Advance online publication. https://doi.org/10.1136/injuryprev-2020-043831

Kochanek, K. D., Murphy, S. L., Xu, J., \& Arias, E. (2019). Deaths: Final data for 2017. National Vital Statistics Reports, 68(9). https://www.cdc.gov/nchs/data/nvsr/nvsr68/nvsr68_09-508.pdf

Kruse, C. S., Krowski, N., Rodriguez, B., Tran, L., Vela, J., \& Brooks, M. (2017). Telehealth and patient satisfaction: a systematic review and narrative analysis. BMJ open, 7(8), e016242. https://doi.org/10.1136/bmjopen-2017-016242

Li, Z., Page, A., Martin, G., \& Taylor, R. (2011). Attributable risk of psychiatric and socio-economic factors for suicide from individual-level, population-based studies: a systematic review. Social science \& medicine (1982), 72(4), 608-616. https://doi.org/10.1016/j.socscimed.2010.11.008

Liang, J., Matheson, B. E., \& Douglas, J. M. (2016). Mental Health Diagnostic Considerations in Racial/Ethnic Minority Youth. Journal of child and family studies, 25(6), 1926-1940. https://doi.org/10.1007/s10826-015-0351-z

Marks, A., Toscano, L., Zeimer, M. (2018). Keys to collaboration between hospital-based violence intervention and cure violence programs. Cure Violence Global.

https://static1.squarespace.com/static/566b074fbfe87338d2021874/t/5b3df65488251b5631c845a7/1530787437553 /Brief_Two_HJA_V6.pdf

McGinty, E. E., \& Webster, D. W. (2017). The Roles of Alcohol and Drugs in Firearm Violence. JAMA internal medicine, 177(3), 324-325. https://doi.org/10.1001/jamainternmed.2016.8192

McGinty, E. E., Choksy, S., \& Wintemute, G. J. (2016). The Relationship Between Controlled Substances and Violence. Epidemiologic reviews, 38(1), 5-31. https://doi.org/10.1093/epirev/mxv008

Mobile Fact Sheet. (2020). https://www.pewresearch.org/internet/fact-sheet/mobile/

National Resource Center on Domestic Violence. (2006). Women of color network facts \& stats: Domestic violence in communities of color.

https:/www.doj.state.or.us/wp-content/uploads/2017/08/women_of_color_network_facts_domestic_violence_2006 .pdf

O'Neal, E. N., \& Beckman, L. O. (2017). Intersections of Race, Ethnicity, and Gender: Reframing Knowledge Surrounding Barriers to Social Services Among Latina Intimate Partner Violence Victims. Violence against women, 23(5), 643-665. https://doi.org/10.1177/1077801216646223

Perron, B. E., Mowbray, O. P., Glass, J. E., Delva, J., Vaughn, M. G., \& Howard, M. O. (2009). Differences in service utilization and barriers among Blacks, Hispanics, and Whites with drug use disorders. Substance abuse treatment, prevention, and policy, 4, 3. https://doi.org/10.1186/1747-597X-4-3

Purtle, J., Rich, L. J., Bloom, S. L., Rich, J. A., \& Corbin, T. J. (2015). Cost-benefit analysis simulation of a hospital-based violence intervention program. American journal of preventive medicine, 48(2), $162-169$. https://doi.org/10.1016/j.amepre.2014.08.030

Roberts, D. W. (2009). Intimate Partner Homicide: Relationships to Alcohol and Firearms. Journal of Contemporary Criminal Justice, 25(1), 67-88. https://doi.org/10.1177/1043986208329771

Roszko, P. J., Ameli, J., Carter, P. M., Cunningham, R. M., \& Ranney, M. L. (2016). Clinician Attitudes, Screening Practices, and Interventions to Reduce Firearm-Related Injury. Epidemiologic reviews, 38(1), 87-110. https://doi.org/10.1093/epirev/mxv005

Saloner, B., \& Lê Cook, B. (2013). Blacks and Hispanics are less likely than whites to complete addiction treatment, largely due to socioeconomic factors. Health affairs (Project Hope), 32(1), 135-145. https://doi.org/10.1377/hlthaff.2011.0983

Sexton, S. M., Lin, K. W., Weiss, B. D., Bunt, C. W., Ebell, M. H., Saguil, A., \& Middleton, J. L. (2018). Preventing Gun Violence: The Role of Family Physicians. American family physician, 98(9), 560-568.

Sheats, K. J., Irving, S. M., Mercy, J. A., Simon, T. R., Crosby, A. E., Ford, D. C., Merrick, M. T., Annor, F. B., \& Morgan, R. E. (2018). Violence-Related Disparities Experienced by Black Youth and Young Adults: Opportunities for Prevention. American journal of preventive medicine, 55(4), 462-469. https://doi.org/10.1016/j.amepre.2018.05.017

Shibru, D., Zahnd, E., Becker, M., Bekaert, N., Calhoun, D., \& Victorino, G. P. (2007). Benefits of a hospital-based peer intervention program for violently injured youth. Journal of the American College of Surgeons, 205(5), 684-689. https://doi.org/10.1016/j.jamcollsurg.2007.05.029 
Smith, R., Dobbins, S., Evans, A., Balhotra, K., \& Dicker, R. A. (2013). Hospital-based violence intervention: risk reduction resources that are essential for success. The journal of trauma and acute care surgery, 74(4), 976-982. https://doi.org/10.1097/TA.0b013e31828586c9

Special Report. U.S. Department of Justice Office of Justice Programs. March 2009, NCJ 225037. http://www.ojp.usdoj.gov/bjs/abstract/anhpivc.htm.

Swanson, J. W., Easter, M. M., Robertson, A. G., Swartz, M. S., Alanis-Hirsch, K., Moseley, D., Dion, C., \& Petrila, J. (2016). Gun Violence, Mental Illness, And Laws That Prohibit Gun Possession: Evidence From Two Florida Counties. Health affairs (Project Hope), 35(6), 1067-1075. https://doi.org/10.1377/hlthaff.2016.0017

U.S. Preventative Services Task Force. (2019). USPSTF A and B Recommendations. https://www.uspreventiveservicestaskforce.org/Page/Name/uspstf-a-and-b-recommendations/

Williamson, H. C., Karney, B. R., \& Bradbury, T. N. (2019). Barriers and facilitators of relationship help-seeking among low-income couples. Journal of family psychology: JFP: Journal of the Division of Family Psychology of the American Psychological Association (Division 43), 33(2), 234-239. https://doi.org/10.1037/fam0000485

Woodward, A. T., Taylor, R. J., Abelson, J. M., \& Matusko, N. (2013). Major depressive disorder among older African Americans, Caribbean blacks, and non-Hispanic whites: secondary analysis of the National Survey of American Life. Depression and anxiety, 30(6), 589-597. https://doi.org/10.1002/da.22041/

\section{Copyrights}

Copyright for this article is retained by the author(s), with first publication rights granted to the journal.

This is an open-access article distributed under the terms and conditions of the Creative Commons Attribution license which permits unrestricted use, distribution, and reproduction in any medium, provided the original work is properly cited. 